\title{
Oxidation of Stainless Steel by Laser Cutting
}

\author{
A. Amulevičius, K. MažEika And Č. Sipavičıus \\ Institute of Physics, Savanoriu 231, LT-02300 Vilnius, Lithuania
}

(Received January 28, 2009; in final form March 31, 2009)

\begin{abstract}
Oxidation of erosion products was studied by means of the Mössbauer spectroscopy and X-ray diffraction methods when the strip of stainless steel was cut with the laser. Different content of wustite and chromium doped magnetite $\mathrm{Fe}_{3-x} \mathrm{Cr}_{x} \mathrm{O}_{4}$ was found in the samples of erosion products depending on the place where the erosion products were collected in relation to the cutting slot. Conversion electron Mössbauer spectroscopy data showed that more magnetite was found at the surface while wustite distributes in the whole volume of particles of erosion products.
\end{abstract}

PACS numbers: 42.62.Cf, 82.80.Ej, 81.65.Mq

\section{Introduction}

The stainless steels are very resistant to the influence of aggressive environment. The corrosion and related phase transitions cause deterioration of structural and operational properties of steel. The resistance to corrosion depends on the properties of the surface. Knowledge of oxidation properties of stainless steel is important for its application at higher temperature. Oxidation of chromium rich steels was studied by applying different methods and oxidation conditions $[1,2]$. Though stationary oxidation of ferrous materials is rather well studied, non-stationary processes taking place when stainless steel is affected by the laser are more complicated and less investigated.

Laser technologies, such as laser cutting, perforation and welding, are currently widely used in machine industry. For example, the finishing laser cutting is used in industry to produce parts of high precision and with a clean edge of the cut. Laser technologies may also be applied to the surface modification or even synthesis of new materials [3-5]. Laser methods such as ablation are used to produce nanostructural materials, among them iron or iron oxide nanoparticles [6]. The oxidation products of iron (iron oxides) produced by the laser can be applied as magnetic materials, pigments for ceramics, paints, as catalysts in chemical technology, etc.

The aim of the study is to investigate peculiarities of oxidation of stainless steel in air flow when short pulses of millisecond duration of the laser are applied to the laser cutting. The X-ray diffraction, Mössbauer spectroscopy transmission and conversion electron methods are used in the study.

\section{Experimental methods}

The strip of stainless steel of 7C27Mo2 Sandvic was cut with the laser (Fig. 1). The steel contained $0.38 \%$ of carbon, $13.5 \%$ of chromium, and $1.0 \%$ of molybdenum. The erosion products, which are produced by cutting when steel melts and is blown from the cutting slot as well as oxidizes during these processes, were collected to make the samples for the X-ray and Mössbauer studies. The samples were made from the material collected in different places. The sample S-7 consisted of erosion products removed from the lower edge of the cutting slot (place 5 in Fig. 1). The material (place 6 in Fig. 1) of the sample S-6 was repeatedly affected (heated) by the laser beam which was out of focus in place 6 . The sample S- 4 was made from the material collected in the filter of the air pump at a distance of $1.5 \mathrm{~m}$. Other samples S-2, S-3, and S-5 were collected at a short distance $(15-20 \mathrm{~mm})$ in the direction of direct air flow (place 7 in Fig. 1).

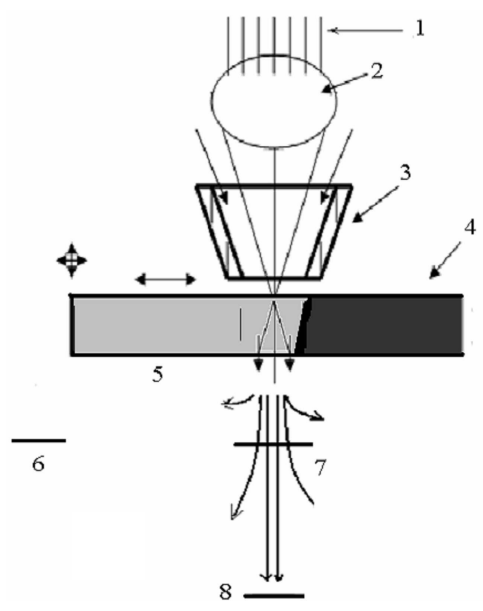

Fig. 1. Scheme of laser cutting of a steel strip. 1 - laser beam, 2 - lens, 3 - nozzle, 4 - steel strip, 5-8 - places of sample collection.

The Nd:YAG laser was applied to cut a steel strip. The duration and frequency of laser pulses, and the average power of the laser were $2 \mathrm{~ms}, 150 \mathrm{~Hz}$ and $160 \mathrm{~W}$, respectively. The laser beam was focused to the spot of the 
diameter of $0.18-0.2 \mathrm{~mm}$ (assuming it to be equal to the width of the cutting slot). The laser cutting velocity of a steel strip was up to $7 \times 10^{-3} \mathrm{~m} / \mathrm{s}$. The air flow was directed to the cutting point by the nozzle. The air pressure in front of the nozzle was 4 bar. During the laser cutting the air flow removes most of the melt from the cutting slot. The air flow is required for the optimization of laser cutting. The melt drops break away from the cutting slot and move with air flow in different directions. Under optimal conditions of the laser power and air flow only a little amount of drops, mainly of "bubble" form, remains on the lower edge of the cutting slot.

For X-ray diffraction studies a DRON-3 diffractometer with $\mathrm{Cu} K_{\alpha}$ line of the wavelength $\lambda=0.1543 \mathrm{~nm}$ was used.

The Mössbauer spectra were registered applying a transmission geometry, except two spectra which were recorded using conversion electron Mössbauer spectroscopy. The ${ }^{57} \mathrm{Co}(\mathrm{Rh})$ source was used. Conversion electron Mössbauer spectra allowed investigating the surface of the samples approximately to $100 \mathrm{~nm}$ depth.

Different subspectra were fitted to Mössbauer spectra taking into consideration the contributions of iron oxides, $\mathrm{Fe}(\mathrm{Cr})$ solid solution and $\sigma$-FeCr phase. Singlets and doublet were used to describe paramagnetic compounds while sextets were applied to take into consideration the contributions of ferromagnetic ones. For magnetite $\mathrm{Fe}_{3} \mathrm{O}_{4}$ two sextets with hyperfine fields of $\approx 46$ and $\approx 49.3 \mathrm{~T}$ were used, while the contribution of hematite was described by sextet with the hyperfine field of $51.9 \mathrm{~T}$. For wustite FeO two subspectra - singlet with the isomer shift $\delta=0.3-0.6 \mathrm{~mm} \mathrm{~s}^{-1}$ relatively to $\alpha$-Fe, as well as doublet with $\delta=0.9-1.1 \mathrm{~mm} \mathrm{~s}^{-1}$ and quadrupole splitting $\Delta=0.7-0.9 \mathrm{~mm} \mathrm{~s}^{-1}$ — were used. The paramagnetic $\sigma$-FeCr phase is usually described by singlets or doublets having isomer shifts which are negative relatively to $\alpha$-Fe $[7,8]$. Due to poor resolution (small $\sigma$-FeCr content) only one singlet with $\delta$ from -0.11 to $-0.08 \mathrm{~mm} \mathrm{~s}^{-1}$ in this study was used to determine the content of this phase.

For $\mathrm{Fe}(\mathrm{Cr})$ solid solutions up to four sextets were used for the Mössbauer spectra description. The sextets having a different hyperfine field correspond to different distribution of $\mathrm{Cr}$ atoms in the first two coordination spheres of an iron atom. One $\mathrm{Cr}$ atom in the first and second coordination spheres causes reduction in the hyperfine field by $\approx 3.15 \mathrm{~T}$ and $\approx 2.25 \mathrm{~T}$, respectively [9]. The probability of an iron atom to have $m \mathrm{Cr}$ atoms in the first coordination sphere and $n \mathrm{Cr}$ atoms in the second one is described by the binomial law

$$
P(m, n)=\left(\begin{array}{c}
8 \\
m
\end{array}\right)\left(\begin{array}{l}
6 \\
n
\end{array}\right) c^{m+n}(1-c)^{14-m-n},
$$

where $c$ is the percentage of impurity (chromium) atoms in the $\mathrm{Fe}(\mathrm{Cr})$ solid solution. Therefore, the percentage $c$ can be evaluated on the basis of probability $P(0,0)$ :

$$
c=1-P(0,0)^{1 / 14} \text {. }
$$

$P(0,0)$, which is the probability of iron atom to have no
Cr atoms in the first two coordination spheres, is evaluated by determining the relative area of corresponding sextet.

\section{Experimental results}

X-ray diffraction patterns of steel and the erosion products are shown in Fig. 2. The qualitative X-ray peaks were not observed for the sample consisting of the erosion products, except one peak at $2 \theta \approx 44^{\circ}$ angle. The peak can be composed of the relatively intensive diffraction peak of $\alpha$-Fe phase and less intense peaks of oxides $\mathrm{FeO}, \mathrm{Fe}_{3} \mathrm{O}_{4}$ and $\sigma$-FeCr phase. In addition, the peak at $2 \theta \approx 36^{\circ}$ angle arises due to the contribution of oxides $\mathrm{FeO}$ and $\mathrm{Fe}_{3} \mathrm{O}_{4}$.

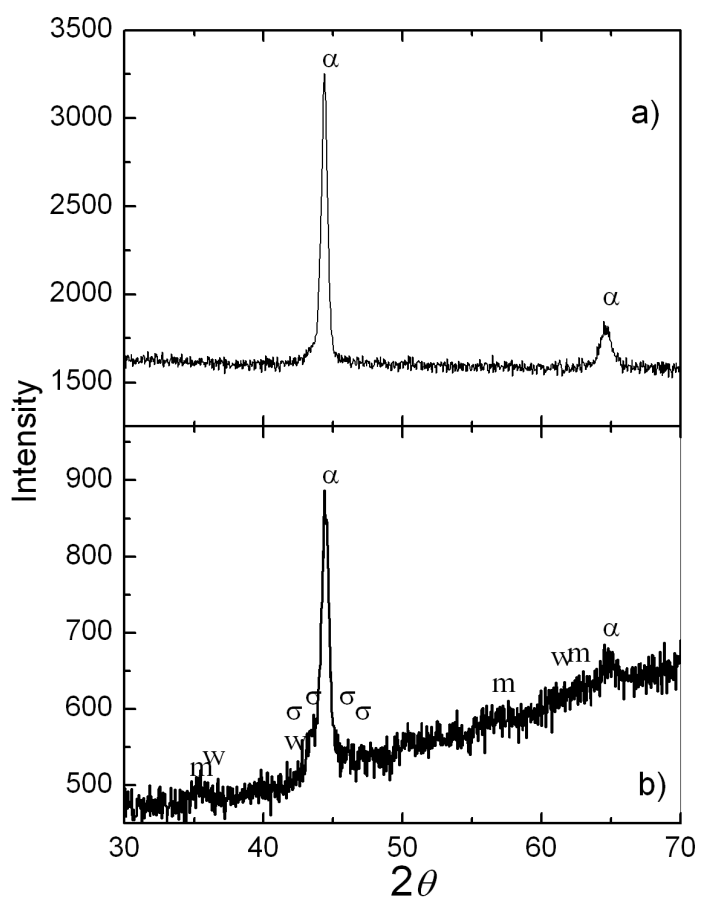

Fig. 2. X-ray diffraction pattern: (a) initial steel, (b) erosion products collected at a short distance from the cutting slot. $\alpha$ is $\alpha-\mathrm{Fe}, \sigma$ is $\sigma$-FeCr, w is wustite, $\mathrm{m}$ is magnetite.

The Mössbauer spectrum of non-affected steel is shown in Fig. 3a. The amount of paramagnetic phases is small. The magnetically split area of spectrum is caused by $\alpha-\mathrm{Fe}(\mathrm{Cr})$ solid solution. According to Eq. (2) the percentage of impurity atoms in solid solution is found to be $11 \pm 3$ at. $\%$.

The changes in the phase structure of samples influenced by laser radiation are reflected in the Mössbauer spectra (Fig. 3). According to their analysis the relative areas of subspectra which are attributed to the phases $\mathrm{Fe}(\mathrm{Cr}), \alpha-\mathrm{Fe}_{2} \mathrm{O}_{3}, \mathrm{Fe}_{3} \mathrm{O}_{4}, \mathrm{FeO}, \sigma$-FeCr are found (Table I). As the area of the Mössbauer spectrum is proportional to the number of iron atoms and the probability of the Mössbauer effect of the phase, the data in Table I 


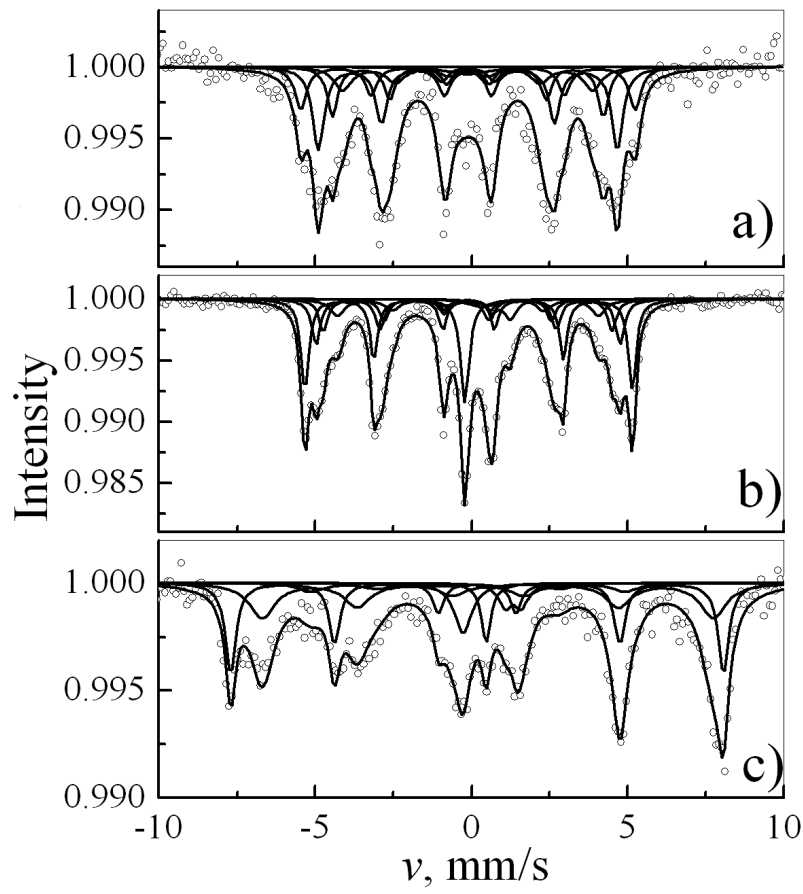

Fig. 3. Mössbauer spectra of samples of: (a) non-affected steel, (b) erosion products with a small content of oxides (sample S-2), (c) erosion products with a large amount of oxides (sample S-4). show contents of iron in the phases if the difference in the probability is neglected. However, for $\alpha$-Fe and iron oxides, the probability may differ approximately by up to $10 \%[10]$.

Some samples have a small amount of oxides, mainly in the form of FeO. These samples consist of erosion products collected at a short distance in the direction of air flow. In the slightly oxidized samples, the amount of iron in $\sigma$-phase increased up to $12 \%$. The percentage of impurities (chromium) in the $\mathrm{Fe}(\mathrm{Cr})$ solid solution decreased to 5 at.\%.

The material of samples having a large amount of oxides was collected in different places. The sample S-6 was collected at the edge (place 6 in Fig. 1), where the erosion products were repeatedly affected by the laser beam which was out of focus at such a distance. It has the largest amount of FeO. The sample S-7 consisted of erosion products swept from the lower edge of the cutting slot. This sample had a large amount of magnetite. During laser cutting the part of the melt which was blown from cutting slot by the air flow remained on the lower edge of the slot in the form of small drops. When optimal power of the laser and gas flow conditions are chosen, these drops oxidize and can be easily removed. The erosion products which had the largest amount of oxides were collected in the filter of the pump at a distance of $1.5 \mathrm{~m}(\mathrm{~S}-4)$.

\section{TABLE I}

Phase distribution of iron of samples. $P(0,0)$ - relative amount of iron atoms having no $\mathrm{Cr}$ atoms in iron first two coordination spheres, $c_{\mathrm{Cr}}$ - the percentage of chromium in the $\mathrm{Fe}(\mathrm{Cr})$ solid solution.

\begin{tabular}{|c|c|c|c|c|c|c|c|}
\hline & \multicolumn{5}{|c|}{ Area [\%] } & \multirow[b]{2}{*}{$P(0,0)$} & \multirow{2}{*}{$\begin{array}{c}c_{\mathrm{Cr}} \\
{[\mathrm{at} . \%]}\end{array}$} \\
\hline & $\mathrm{Fe}(\mathrm{Cr})$ & $\alpha-\mathrm{Fe}_{2} \mathrm{O}_{3}$ & $\mathrm{Fe}_{3} \mathrm{O}_{4}$ & $\mathrm{FeO}$ & $\sigma$-phase & & \\
\hline $\mathrm{S}-1^{a}$ & $95 \pm 2$ & - & - & $2 \pm 2$ & $3 \pm 2$ & $0.2 \pm 0.1$ & $11 \pm 3$ \\
\hline S-2 & $76 \pm 2$ & - & - & $14 \pm 1$ & $10 \pm 1$ & $0.38 \pm 0.01$ & $7 \pm 1$ \\
\hline S-3 & $75 \pm 3$ & - & - & $13 \pm 2$ & $12 \pm 2$ & $0.28 \pm 0.05$ & $9 \pm 1$ \\
\hline S-4 & $11 \pm 1$ & - & $73 \pm 2$ & $7 \pm 1$ & $9 \pm 1$ & - & - \\
\hline S-5 & $70 \pm 3$ & - & - & $23 \pm 3$ & $7 \pm 1$ & $0.49 \pm 0.04$ & $5 \pm 1$ \\
\hline $\mathrm{S}-5^{c}$ & $43 \pm 5$ & - & $32 \pm 7$ & $20 \pm 3$ & $5 \pm 3$ & - & - \\
\hline S-6 & $37 \pm 4$ & - & $21 \pm 3$ & $33 \pm 4$ & $9 \pm 2$ & $0.20 \pm 0.07$ & $11 \pm 2$ \\
\hline $\mathrm{S}-6^{b}$ & $41 \pm 4$ & $17 \pm 1$ & $28 \pm 2$ & $14 \pm 4$ & - & $0.48 \pm 0.07$ & $5 \pm 1$ \\
\hline $\mathrm{S}-6^{c}$ & $24 \pm 4$ & - & $44 \pm 5$ & $32 \pm 6$ & - & - & - \\
\hline S-7 & $42 \pm 2$ & - & $40 \pm 2$ & $9 \pm 1$ & $9 \pm 1$ & - & - \\
\hline
\end{tabular}

The thermal effect of laser irradiation on the steel surface can be evaluated by numerically solving the heat equation. The simulation provides temperature at the surface and below it, as shown in Fig. 4. For simplicity, the thermodynamic parameters for pure iron are taken. It is evident that the ability of the laser cutting depends on achieved temperature and the quantity of laser pulses which irradiate the cutting place. The velocity of movement of the laser beam $v=7 \times 10^{-3} \mathrm{~m} / \mathrm{s}$, the effective diameter of the laser beam $d=0.2 \mathrm{~mm}$ and the absorption efficiency of the laser power of 0.23 are taken for the simulation. The maximum temperature of the surface of steel during laser irradiation depends on the laser beam focusing but it could not be higher than the boiling point. 
TABLE II

Hyperfine parameters of magnetite Mössbauer subspectra $(A, B)$.

\begin{tabular}{l|c|c|c|c|c|c}
\hline \hline & $\Gamma_{A}\left[\mathrm{~mm} \mathrm{~s}^{-1}\right]$ & $\delta_{A}\left[\mathrm{~mm} \mathrm{~s}^{-1}\right]$ & $B_{A}[\mathrm{~T}]$ & $\Gamma_{B}\left[\mathrm{~mm} \mathrm{~s}^{-1}\right]$ & $\delta_{B}\left[\mathrm{~mm} \mathrm{~s}^{-1}\right]$ & $B_{B}[\mathrm{~T}]$ \\
\hline magnetite $^{a}$ & $0.31 \pm 0.01$ & $0.29 \pm 0.01$ & $49.3 \pm 0.01$ & $0.36 \pm 0.01$ & $0.67 \pm 0.01$ & $46.05 \pm 0.01$ \\
S-4 & $0.42 \pm 0.03$ & $0.29 \pm 0.01$ & $48.9 \pm 0.06$ & $0.97 \pm 0.06$ & $0.64 \pm 0.02$ & $44.8 \pm 0.1$ \\
$\mathrm{~S}^{c}{ }^{c}$ & $0.5 \pm 0.2$ & $0.25 \pm 0.04$ & $48.9 \pm 0.4$ & $1.15 \pm 0.32$ & $0.77 \pm 0.09$ & $47.2 \pm 0.6$ \\
$\mathrm{~S}-6$ & $0.29 \pm 0.05$ & $0.30 \pm 0.02$ & $49.4 \pm 0.1$ & $0.88 \pm 0.17$ & $0.64 \pm 0.05$ & $46.0 \pm 0.4$ \\
$\mathrm{~S}^{b} 6^{b}$ & $0.33 \pm 0.05$ & $0.30 \pm 0.01$ & $49.5 \pm 0.1$ & $0.57 \pm 0.07$ & $0.61 \pm 0.02$ & $45.7 \pm 0.13$ \\
$\mathrm{~S}^{c}{ }^{c}$ & $1.08 \pm 0.17$ & $0.39 \pm 0.04$ & $49.6 \pm 0.3$ & - & - & - \\
S-7 & $0.38 \pm 0.02$ & $0.26 \pm 0.01$ & $48.83 \pm 0.05$ & $0.87 \pm 0.07$ & $0.62 \pm 0.02$ & $45.1 \pm 0.32$ \\
\hline
\end{tabular}

${ }^{a}$ bulk magnetite (Aldrich); ${ }^{b}$ annealed sample; ${ }^{c}$ conversion electron spectrum

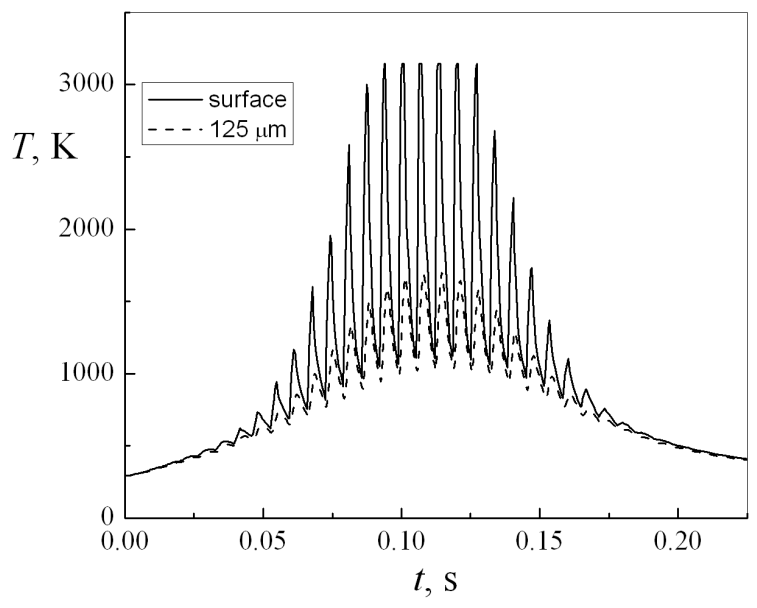

Fig. 4. Dependence of temperature on laser irradiation time when the laser beam passes the selected point.

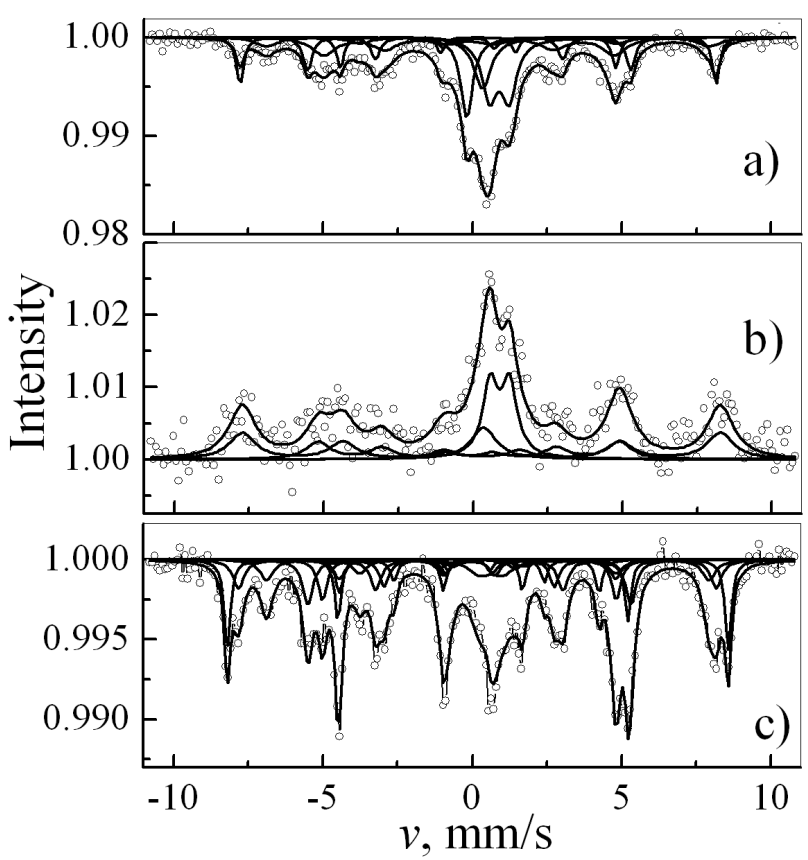

Fig. 5. Mössbauer spectra of sample S-6: (a) transmission spectrum, (b) CEMS, (c) spectrum of the sample annealed at $800 \mathrm{~K}$.

\section{Discussion}

The transmission and conversion electron Mössbauer spectra of the same sample (S-5, S-6) allowed us to compare the composition at the surface and in the bulk. The relative content of magnetite was much larger at the surface, while the content of wustite was approximately the same (Table I). Wustite forms at high temperature during laser processing. The melt may oxidize to $\mathrm{Fe}_{3} \mathrm{O}_{4}$ when it quenches after the laser pulse, but after a sequence of laser pulses previously formed iron oxides may decompose. The melted mass of steel intensively mixes because of surface tensions [11]. The air flow when it removes the melt from the cutting slot also helps to bury formed wustite inside the bulk. Magnetite may form later, when hot erosion products are in the air flow and in the place where they were collected. Therefore, a larger amount of lution was lower and the relative amount of magnetite was higher. ume of the sample and that on the surface, two samples - the sample S-6 before annealing and slightly oxidized sample S-5 - were measured using the conversion electron Mössbauer spectroscopy (Fig. 5). It was determined that on the surface the amount of initial $\mathrm{Fe}(\mathrm{Cr})$ solid so- 
magnetite was found on the surface. When the melt cools down, it is possible that wustite decomposes according to the equation $4 \mathrm{FeO} \Rightarrow \mathrm{Fe}_{3} \mathrm{O}_{4}+\alpha$-Fe, for example, when the defocused laser beam heats up the material many times as in case of sample S-6. However, a similar content of wustite at the surface and in the whole volume of the samples indicates that its content may not change during cooling down. In addition, in other samples, magnetite was not found, though wustite was observed. Therefore, the increase in the magnetite content at the surface can be explained only by additional oxidation of $\mathrm{Fe}(\mathrm{Cr})$ which occurs after the formation of drops and removal of erosion products from the cutting slot. The decay of wustite was clearly observed only when the sample S-6 was annealed at temperature of $800 \mathrm{~K}$ much longer than the duration of the laser irradiation. As a consequence, the $\mathrm{Fe}(\mathrm{Cr})$ content increased.

It is evident that the additional heating with the defocused laser beam enhances the formation of magnetite in the sample S-6. The size of drops of erosion products is also important. In the filter of the pump only very small particles, of which the sample S-4 was made, were collected. The sample was mainly composed of magnetite. The decrease in the hyperfine field of magnetite $A$ sublattice by $\approx 1 \%$ (Table II) is observed, which may show the influence of superparamagnetic relaxation arising due to nanometric sizes of particles. However, for magnetite $B$ subblattice, the hyperfine field decreased even more $(\approx 3 \%)$. As in the case of steel where chromium atoms influence the hyperfine field of iron, the observed decrease in the hyperfine field for both sublattices of magnetite can be explained by the substitution of iron atoms by chromium ones in $B$ sublattice [12].

Presence of chromium is an important factor influencing the oxidation of stainless steel because the compounds such as $\mathrm{Cr}_{2} \mathrm{O}_{3}$ and $\mathrm{Fe}_{3-x} \mathrm{Cr}_{x} \mathrm{O}_{4}$ may form [1, 2], though only iron containing oxides are determined by means of the Mössbauer spectroscopy. As it is shown in Table I the changes in the percentage of chromium in $\mathrm{Fe}(\mathrm{Cr})$ solution and in the content of $\sigma$-FeCr phase are observed, indicating mobility of chromium in erosion products obtained by the laser cutting. In addition, chromium modifies magnetite by forming $\mathrm{Fe}_{3-x} \mathrm{Cr}_{x} \mathrm{O}_{4}$.

Chromium atoms occupy sites in $B$ sublattice of magnetite. The corresponding Mössbauer subspectrum is broadened because of the distribution of the hyperfine field $B_{B}$ which decreases if chromium atoms are between nearest neighbors of an iron atom. The increase in the line width is observed for our samples (Table II) because only one sextet is applied to $B$ sublattice. In much more complicated description [12] the area of Mössbauer spectrum attributed to $B$ sublattice is divided to the areas of up to six sextets having different hf field and relative intensity. It is assumed that $\mathrm{Cr}$ atoms distribute randomly and one $\mathrm{Cr}$ atom in the neighborhood of iron atom causes a decrease of 1.1-1.7 $\mathrm{T}$ in the hyperfine field.

For magnetite subspectra of our samples the line width corresponding to $B$ sublattice is in most cases more than twice broader than for the bulk magnetite (Aldrich). The exception is the annealed sample S-6. Because of the annealing the line width decreases. The decrease can be explained that magnetite has less chromium taking into consideration the influence of chromium on broadening of line width. It was also found that the chromium percentage in $\mathrm{Fe}(\mathrm{Cr})$ solution also decreased (Table I). Therefore, most probably chromium forms separate oxide phase $\mathrm{Cr}_{2} \mathrm{O}_{3}$ because of annealing. When annealing at above $800^{\circ} \mathrm{C}$, the layer of chromium oxide is usually found on the top of the surface of steel. At lower temperature iron oxides are also found [2]. Chromium rich steel 7C27Mo2 Sandvic is mainly composed of $\mathrm{Fe}(\mathrm{Cr})$ solid solution (Table I), which is metastable at room temperature according to $\mathrm{Fe}-\mathrm{Cr}$ phase diagram. Aging or annealing of metastable iron-chromium alloys causes the decomposition to Fe-rich and Cr-rich phases by spinodal decomposition or nucleation and growth on nanoscale $(\approx 5 \mathrm{~nm})[13,14]$. Admittedly, at elevated temperatures the diffusion of chromium is faster. For the diffusion coefficient of chromium at temperatures achieved by the laser (at $T=2000-3000 \mathrm{~K}$ diffusion coefficient is $D \approx 6 \times 10^{-12}--3 \times 10^{-9} \mathrm{~m}^{2} \mathrm{~s}^{-1}$ ) and the $2 \mathrm{~ms}$ laser pulse duration, the diffusion length of $\approx 100 \mathrm{~nm}-3 \mu \mathrm{m}$ is sufficiently large to form separate $\sigma$-FeCr and chromium oxide phases on the surface of the grains. The formation of the Cr oxide layer on the surface can prevent the oxidation of iron in the bulk.

\section{Conclusions}

Depending on conditions of the laser cutting and the place where the erosion products were collected, $13-80 \%$ of iron of the samples was in oxide phases. Among them the contents in wustite $\mathrm{FeO}$ and magnetite $\mathrm{Fe}_{3} \mathrm{O}_{4}$ were $7-33 \%$ and $0-73 \%$, respectively. The largest amount of wustite was found when the material was heated (annealed) many times with the defocused laser beam. The largest amount of magnetite was observed in dispersive nanocrystalline erosion products collected in the filter of the air pump. On the contrary, erosion products made of large drops collected just below the cutting slot contained only a small amount of wustite. Conversion electron Mössbauer spectra have shown that the surface of samples is more oxidized and contains a larger amount of magnetite. According to the Mössbauer spectroscopy some iron atoms in $B$ sublattice of magnetite were replaced by chromium atoms, and the formation of mixed spinel $\mathrm{Fe}_{3-x} \mathrm{Cr}_{x} \mathrm{O}_{4}$ was observed. On the contrary, hematite $\mathrm{Fe}_{2} \mathrm{O}_{3}$ as well as mixed with eskolaite $\mathrm{Cr}_{2} \mathrm{O}_{3}$ were not observed, except the sample annealed at $800 \mathrm{~K}$.

\section{References}

[1] C.E. Reis de Carvalho, G. Magela da Costa, A. Barros Cota, E.H. Rossi, Mater. Res. 9, 393 (2006).

[2] A. Vesel, M. Mozetič, A. Zalar, Appl. Surf. Sci. 200, $94(2002)$ 
[3] A. Amulevicius, M. Balciuniene, B. Petretis, R. Pileckis, Thin Solid Films 240, 60 (1994).

[4] A. Amulevicius, K. Mazeika, A. Daugvila, J. Phys. D, Appl. Phys. 33, 1985 (2000).

[5] A. Amulevicius, A. Daugvila, R. Davidonis, K. Mazeika, Acta Phys. Pol. A 104, 537 (2003).

[6] M. Ullmann, S.K. Friedlander, A. Schmidt-Ott, J. Nanopart. Res. 4, 499 (2002).

[7] J. Cieślak, B.F.O. Costa, S.M. Dubiel, G. Le Caër, Phys. Rev. B 73, 184123 (2006).

[8] J. Cieślak, B.F.O. Costa, S.M. Dubiel, M. Reissner, W. Steiner, J. Phys., Condens. Matter 17, 2985 (2005).

[9] S.M. Dubiel, J. Zukrowski, Acta Phys. Pol. A 58, 37 (1980).
[10] Yi-Long Chen, De-Ping Yang, Mössbauer Effect in Lattice Dynamics. Experimental Techniques and Applications, Wiley-VCH, Weinheim 2007, p. 409.

[11] X. He, P.W. Fuerschbach, T. DebRoy, J. Phys. D, Appl. Phys. 36, 1388 (2003).

[12] Hang Nam Ok, Lu San Pan, B.J. Evans, Phys. Rev. B 17, 85 (1978).

[13] J. Cieślak, S.M. Dubiel, B. Sepiol, J. Phys., Condens. Matter 12, 6709 (2000)

[14] M.K. Miller, J.M. Hyde, M.G. Hetherington, A. Cerezo, G.D.W. Smith, C.M. Elliott, Acta Metall. Mater. 43, 3385 (1995). 